\title{
Chapter 12 \\ Structural Relaxation of Oxide \\ Compounds from the High-Pressure Phase
}

\author{
Hitoshi Yusa
}

\begin{abstract}
In this chapter, several types of structural relaxation of oxide compounds from the high-pressure phase are systematically introduced in terms of high-pressure comparative crystallography. Structural relaxation of various $\mathrm{ABO}_{3}$ compounds from the perovskite phase to the lithium niobate phase is explained in detail from rotation of the $\mathrm{BO}_{6}$ octahedral frameworks. Depressurized amorphization of $\mathrm{ASiO}_{3}$ perovskites containing large divalent cations $\left(\mathrm{A}=\mathrm{Ba}^{2+}, \mathrm{Sr}^{2+}\right.$, and $\mathrm{Ca}^{2+}$ ) is elucidated by the characteristics of the hexagonal and cubic perovskite structures. The unquenchable $\mathrm{Rh}_{2} \mathrm{O}_{3}$ (II) phases of group-13 sesquioxides, such as $\mathrm{Ga}_{2} \mathrm{O}_{3}$ and $\mathrm{In}_{2} \mathrm{O}_{3}$, are confirmed by both experimental and computational studies. $\mathrm{Ab}$ initio calculations of $\mathrm{Y}_{2} \mathrm{O}_{3}$ show that the unquenchable pressure-induced phase (A-type structure) is not the stable phase under high pressure. Knowledge about the unquenchable and/or metastable phases in recovered high-pressure products is beneficial for advanced computational materials design.
\end{abstract}

Keywords High-pressure experiments - Structural relaxation • Quenchability Amorphization - Ab initio calculation

\subsection{General}

Under high pressure, typical $\mathrm{ABO}_{3}$ oxide compounds undergo a phase transition with the coordination of the $\mathrm{B}$ atoms changing from tetrahedral to octahedral. For the most popular $\mathrm{MgSiO}_{3}$ compounds, which are believed to be one of the most abundant constituent minerals in the Earth's mantle, the crystal structure changes from pyroxene to spinel (ringwoodite) plus stishovite, ilmenite (akimotoite), garnet (majorite), perovskite (bridgmanite), and postperovskite [1, 2]. All of the structures are quenchable, except for the postperovskite structure $\left(\mathrm{CaIrO}_{3}\right.$ structure) which appears under ultrahigh pressure above $140 \mathrm{GPa}$ [2]. Therefore, the physical

\footnotetext{
H. Yusa (訩

National Institute for Materials Science, Namiki 1-1, Tsukuba, Ibaraki, Japan e-mail: YUSA.Hitoshi@nims.go.jp

(C) The Author(s) 2018

I. Tanaka (ed.), Nanoinformatics, https://doi.org/10.1007/978-981-10-7617-6_12
} 
properties of most of the recovered structures can be investigated under ambient pressure. In this case, even the equilibrium phase boundary can be thermodynamically determined by measuring the enthalpy and heat capacity at ambient pressure [1, 3]. However, the high-pressure phase is not always quenchable. Because high-pressure phases tend to undergo structural relaxation during decompression, the high-pressure structures cannot be characterized from the recovered products. The structure can be elucidated by in situ X-ray observation under pressure. In particular, a synchrotron radiation X-ray source combined with a diamond anvil cell (DAC) can shed light on the real structure of the unquenchable phase under pressure.

Some high-pressure perovskites in $\mathrm{ABO}_{3}$ compounds exhibit unquenchable phenomena during decompression to atmospheric pressure. There are two types of structure instability: conversion to perovskite-related structures and amorphization. Structural relaxation in the former case accompanies a symmetry change to a non-centrosymmetric structure, retaining the ferroelectricity. The representative example is structural relaxation from the orthorhombic perovskite structure to the lithium niobate structure. Many compounds with the lithium niobate structure have been found by high-pressure synthesis.

In other simple oxides, there are peculiar high-pressure phases in sesquioxides that revert to a lower pressure phase under room temperature. In some cases, there are definite crystallographic relationships between their lower pressure phases.

$\mathrm{Ab}$ initio computational studies are indispensable to confirm whether the phase appearing by structural relaxation is metastable. Recent computational studies have predicted novel materials with high-performance functionalities. In particular, a data-driven material design approach has identified many candidates for high-pressure synthetic materials. However, the predicted materials are not always realized in the recovered products because of structural relaxation during decompression. To enhance the capability of material design by computational approaches, systematic information about structure relaxation would be highly beneficial.

In this chapter, we focus on relaxation structure and quenchability from the high-pressure phase. By classifying the relaxation process, we discuss the recovery compounds from high-pressure synthesis.

\subsection{Phase Transition from the Perovskite Structure to the Lithium Niobate Structure}

\subsubsection{Crystal Structure Relationship Among Lithium Niobate, Perovskite, and Ilmenite Phases}

The typical lithium niobate phase of Li-bearing compounds, which is represented by $\mathrm{LiNbO}_{3}$ and $\mathrm{LiTaO}_{3}$, is only found in similar lithium-bearing compounds, such as $\mathrm{LiUO}_{3}$ [4] and $\mathrm{LiReO}_{3}$ [5], and all of these lithium niobate phases show stability 
Fig. 12.1 Lithium niobate structure

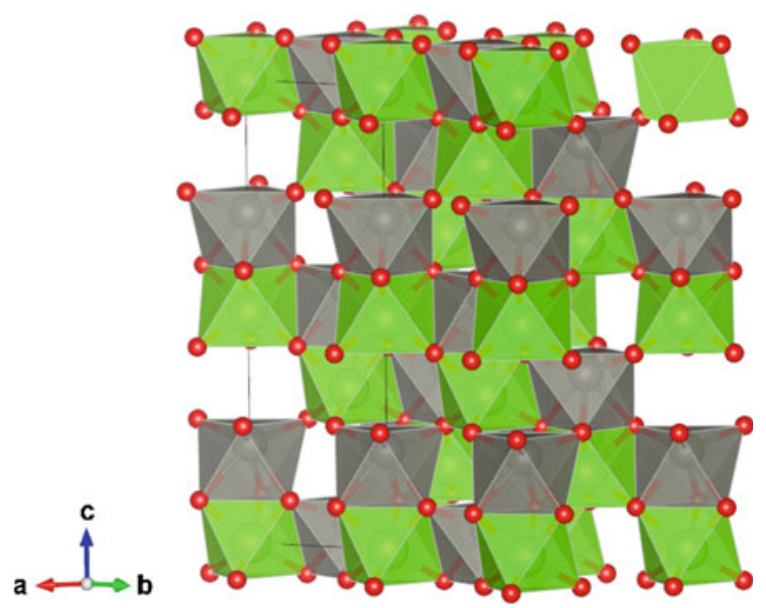

under ambient conditions. In contrast, high-pressure synthesis makes it possible to crystallize lithium niobate phases of various Li-free compounds, such as $\mathrm{A}^{2+} \mathrm{B}^{4+} \mathrm{O}_{3}$-type [6-13] and $\mathrm{A}^{4+} \mathrm{B}^{2+} \mathrm{O}_{3}$-type [14] oxides. One of the lithium niobate structures is shown in Fig. 12.1. It is widely known that lithium niobate phases appear with retrogressive transition from high-pressure perovskite phases. Such a hidden perovskite phase is difficult to confirm with only the recovered high-pressure products, but it has been directly elucidated by in situ experiments under high pressure [6-9, 12-14].

It should be noted that these lithium niobate phases convert from the perovskite structure with structural relaxation during decompression, which is closely related to the rotation of $\mathrm{BO}_{6}$ octahedra. This is a first-order transformation accompanied by a $2-3 \%$ volume change. The typical structural relationship among the ilmenite, perovskite, and lithium niobate phases is shown in Fig. 12.2. As shown in Fig. 12.2, where a specific crystallographic orientation is chosen, the transformation from lithium niobate to perovskite appears to be much easier than that from the ilmenite structure to the perovskite structure. In other words, there must be large displacement of the $\mathrm{BO}_{6}$ octahedra to trigger the ilmenite-perovskite transition, where atomic rearrangement should be controlled by diffusion under high temperature. In fact, for many $\mathrm{ABO}_{3}$ compounds, the perovskite to ilmenite transition is not observed at room temperature throughout the pressure range even though the density of ilmenite is smaller than that of lithium niobate.

\subsubsection{Perovskite Tolerance Factor}

It is believed that such instability is closely correlated with the ionic radii of the Aand B-site cations forming the perovskite structure. The Goldschmidt tolerance 


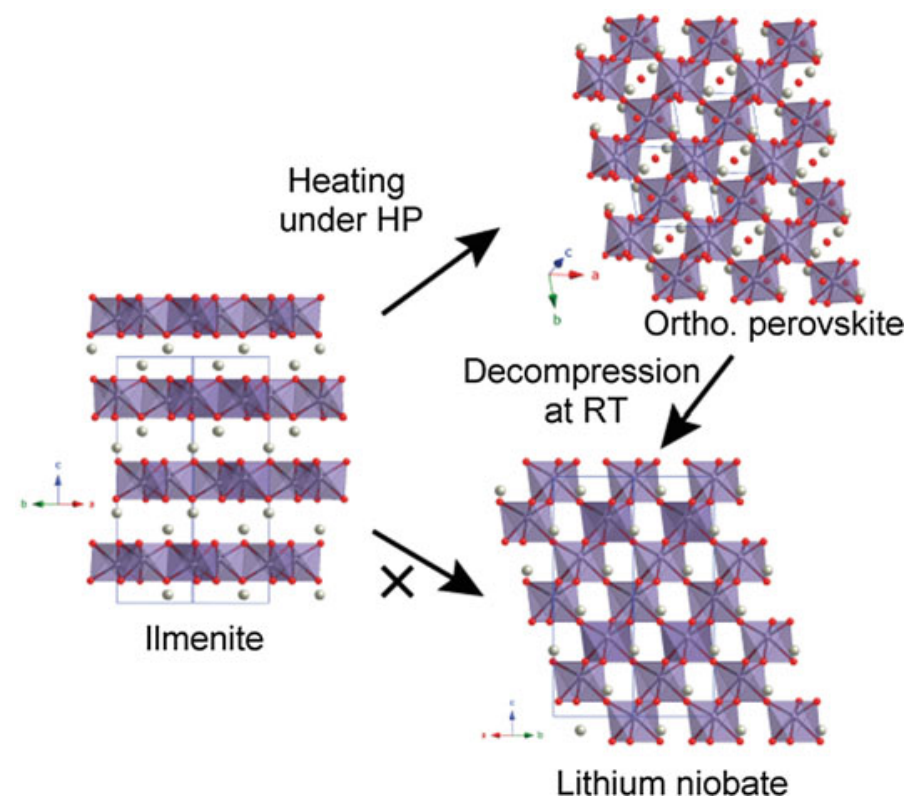

Fig. 12.2 Structural relationship among ilmenite, lithium niobate, and orthorhombic perovskite

factor [15] indicates the distortion from ideal cubic perovskite and it is also applicable to such instabilities during decompression: $t=\left(r_{\mathrm{A}}+r_{\mathrm{o}}\right) / \sqrt{ } 2\left(r_{\mathrm{B}}+r_{\mathrm{O}}\right)$, where $r$ is the effective ionic radius of each element [16]. The tolerance factor is determined from the geometrical relationship of the ionic radii, as shown in Fig. 12.3. The right-hand side figures show the polyhedral types of the A-site cations. Ideal cubic perovskite $(t=1)$ is composed of cubo-octahedral coordinated A cations. Orthorhombic distortion $(t<1)$ incorporates A-site cations, forming square-antiprism-type polyhedra.

The Goldschmidt diagram is useful for understanding the degree of distortion from the ideal perovskite structure. The cation radius ratios of various $\mathrm{ABO}_{3}$ compounds are plotted in the Goldschmidt diagram in Fig. 12.4. In Fig. 12.4, the white arrow indicates compounds in the lower right region that tend to convert to the lithium niobate phase, whereas the black arrow indicates compounds in the upper left region that tend to retain the perovskite structure. This trend means that orthorhombic distortion induces conversion to the lithium niobate phase. Orthorhombic distortion is derived from rotation of $\mathrm{BO}_{6}$ octahedra. Therefore, rotation of $\mathrm{BO}_{6}$ octahedra can be used to understand the degree of rotation for conversion to the lithium niobate structure. O'Keeffe et al. [17] suggested that a single rotation $\Phi$ about the triad [111] axis of a pseudocubic perovskite lattice (the direction is indicated in Fig. 12.3) can be represented as rotation of the $\mathrm{BO}_{6}$ 


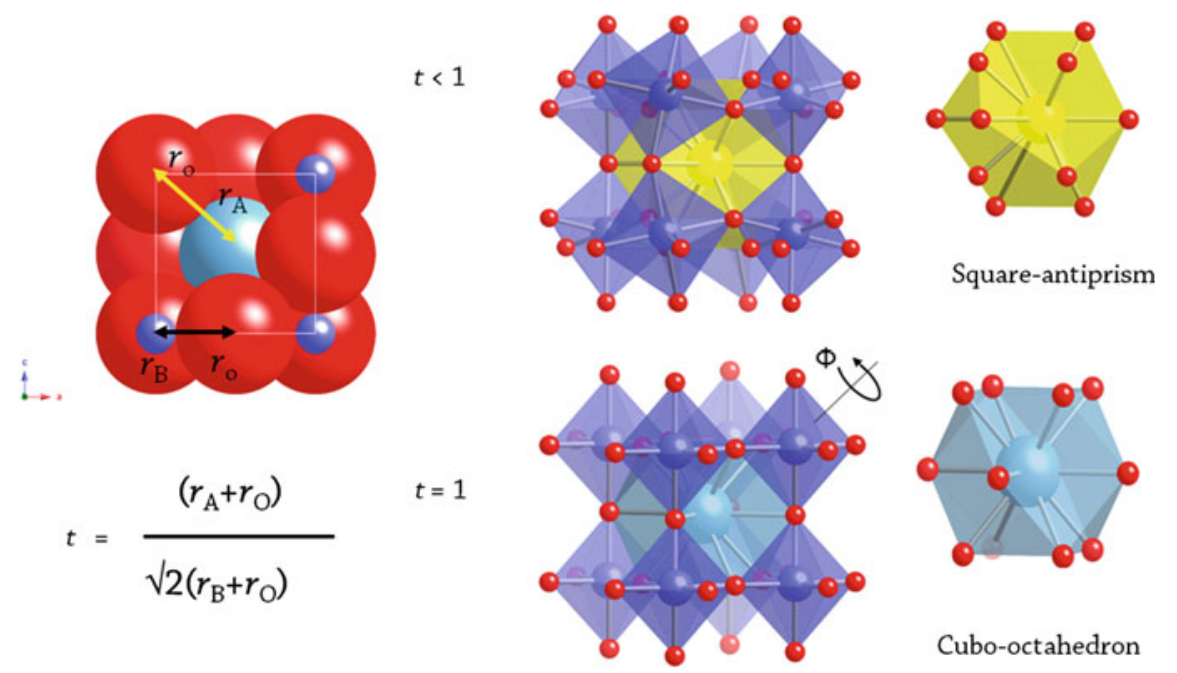

Fig. 12.3 Left: geometrical explanation of the perovskite tolerance factor. Right: orthorhombic $(t<1)$ and cubic perovskite $(t=1)$ polyhedra

Fig. 12.4 Goldschmidt diagram with tolerance factor ( $t$ ) of $\mathrm{ABO}_{3}$ compounds. The tolerance factors (dashed lines) were calculated from the ionic radii of the six-fold coordinated $\mathrm{B}$ cations ( $x$ axis) and eight-fold coordinated $\mathrm{A}$ cations ( $y$ axis). Open squares are compounds that convert to the lithium niobate structure under decompression. Solid squares are compounds that quench as the perovskite structure at ambient pressure

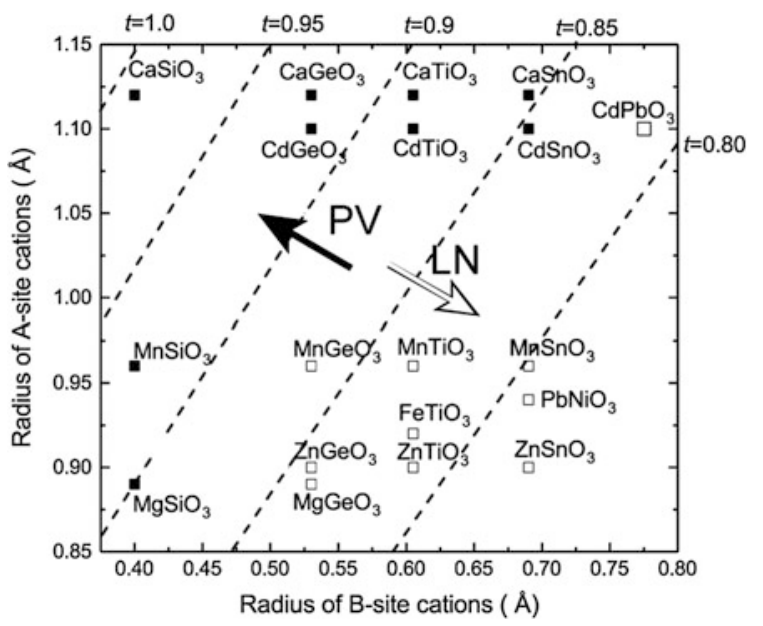

octahedra. The angle can be calculated from the atomic coordinates [18] or estimated from the cell dimensions: $\Phi=\cos ^{-1}\left(\sqrt{ } 2 c^{2} / a b\right)$ [17, 19]. According to the calculated $\Phi$ values of the various perovskite compounds listed in Table 12.1, the critical angle for conversion is estimated to be $15^{\circ}-16^{\circ}$, except for $\mathrm{MgSiO}_{3}$ perovskites. This value is useful for exploring compositions that may adopt the lithium niobate structure. 
Table 12.1 Tilting angle of the $\mathrm{BO}_{6}$ octahedra and lattice parameters of various perovskites

\begin{tabular}{|c|c|c|c|c|c|}
\hline Compound & $a(\AA)$ & $b(\AA)$ & $c(\AA)$ & $\begin{array}{l}\Phi \\
(\operatorname{deg})\end{array}$ & Reference \\
\hline $\mathrm{CaGeO}_{3}$ & 5.2607 & 5.2688 & 7.4452 & 3.9 & Susaki + (1983) [20] \\
\hline $\mathrm{CdGeO}_{3}$ & 5.209 & 5.253 & 7.434 & 10.7 & Susaki (1989) [21] \\
\hline $\mathrm{MnGeO}_{3}(21.8 \mathrm{GPa})$ & 4.9298 & 5.0586 & 7.0873 & 16.5 & Yusa + (2014) [22] \\
\hline $\mathrm{ZnGeO}_{3}(15.6 \mathrm{GPa})$ & 4.8796 & 5.0129 & 7.1233 & 19.4 & Yusa + (2006) [9] \\
\hline $\mathrm{MgGeO}_{3}(17.9 \mathrm{GPa})$ & 4.832 & 5.031 & 7.022 & 20.8 & $\begin{array}{l}\text { Leinenweber + (1994) } \\
\text { [7] }\end{array}$ \\
\hline $\mathrm{CaTiO}_{3}$ & 5.3796 & 5.4423 & 7.6401 & 10.2 & Sasaki + (1987) [23] \\
\hline $\mathrm{CdTiO}_{3}$ & 5.3053 & 5.4215 & 7.6176 & 15.5 & Sasaki + (1987) [23] \\
\hline $\mathrm{MnTiO}_{3}(4.45 \mathrm{GPa})$ & 5.1048 & 5.3046 & 7.4180 & 20.5 & Ross + (1989) [24] \\
\hline $\mathrm{FeTiO}_{3}(16.2 \mathrm{GPa})$ & 5.04 & 5.17 & 7.27 & 17.1 & $\begin{array}{l}\text { Leinenweber + (1991) } \\
\text { [6] }\end{array}$ \\
\hline $\begin{array}{l}(\mathrm{Mg}, \mathrm{Fe}) \mathrm{TiO}_{3}(21 \\
\mathrm{GPa})\end{array}$ & 4.9852 & 5.2104 & 7.2305 & 21.1 & Linton + (1991) [8] \\
\hline $\mathrm{CdSnO}_{3}$ & 5.547 & 5.577 & 7.867 & 7.3 & Smith (1960) [25] \\
\hline $\mathrm{MnSnO}_{3}(7.35 \mathrm{GPa})$ & 5.301 & 5.445 & 7.690 & 18.4 & $\begin{array}{l}\text { Leinenweber +(1991) } \\
\text { [6] }\end{array}$ \\
\hline $\mathrm{MnSiO}_{3}(40 \mathrm{GPa})$ & 4.7559 & 4.8073 & 6.7723 & 10.7 & Fujino + (2009) [26] \\
\hline $\mathrm{ZnTiO}_{3}(21 \mathrm{GPa})$ & 4.9324 & 5.1148 & 7.2514 & 21.9 & Akaogi + (2015) [27] \\
\hline $\mathrm{CaSnO}_{3}$ & 5.5142 & 5.6634 & 7.8816 & 15.6 & Zhao + (2004) [28] \\
\hline $\mathrm{MgSiO}_{3}$ & 4.7754 & 4.9292 & 6.8969 & 18.4 & Horiuchi + (1987) [29] \\
\hline $\mathrm{PbNiO}_{3}$ (c.a. 1 atm) & 5.358 & 5.463 & 7.705 & 15.3 & Inaguma + (2010) [30] \\
\hline $\mathrm{CdPbO}_{3}(1.4 \mathrm{GPa})$ & 5.639 & 5.724 & 8.135 & 15.0 & Yusa + , in preparation \\
\hline $\mathrm{ZnSnO}_{3}(20.2 \mathrm{GPa})$ & 5.1640 & 5.2546 & 7.4455 & 15.4 & Yusa + , in preparation \\
\hline
\end{tabular}

\subsubsection{Structure Stability from a Computational Viewpoint}

$\mathrm{Ab}$ initio calculations provide useful information about the phase stability under high pressure. Enthalpy calculations have revealed the structural stability of the perovskite, lithium niobate, and ilmenite phases of several compounds. All of the lithium niobate phases are metastable under pressure. As an example, the relative differences of the enthalpies of the three phases of $\mathrm{ZnGeO}_{3}$ perovskite are plotted as a function of pressure in Fig. 12.5. The lower pressure phase (the imenite structure) directly change to the perovskite structure. Therefore, we can conclude that the lithium niobate phase is a metastable structure of $\mathrm{ZnGeO}_{3}$ [22]. Similar trends have been found for $\mathrm{MnTiO}_{3}$ [31], $\mathrm{MgGeO}_{3}$ [32], and $\mathrm{ZnTiO}_{3}$ [10] by enthalpy calculations. A further transformation from the perovskite structure to the postperovskite structure has been confirmed for $\mathrm{ZnGeO}_{3}$ [22] and $\mathrm{MgGeO}_{3}$ [32]. 
Fig. 12.5 Enthalpy

differences of the ilmenite (blue triangles) and lithium niobate (red squares) phases of $\mathrm{ZnGeO}_{3}$ relative to the perovskite phase (black diamonds)

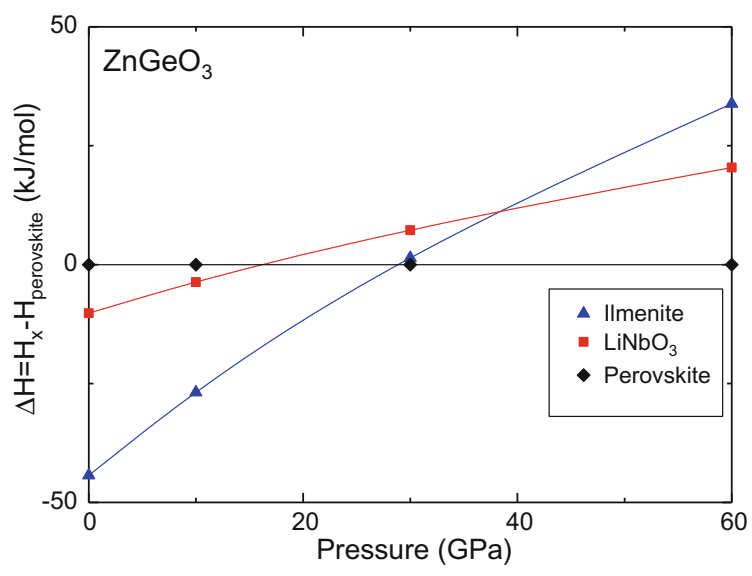

\subsection{Amorphization from Cubic and Hexagonal Silicate Perovskites}

\subsubsection{Phase Transition Sequence of Silicate Perovskites}

For a tolerance factor less than one, as represented by $\mathrm{MgSiO}_{3}$ perovskite, the $\mathrm{BO}_{6}$ octahedra in the perovskite structure tilts to make an allowance for the small divalent cations in the $\mathrm{BO}_{6}$ octahedral corner-sharing framework. The tilting in perovskite has been discussed in detail by many researchers (e.g., Glazer [33]), where rotation does not disrupt the corner-sharing connectivity. As mentioned in Sect. 12.2, if rotation of the $\mathrm{BO}_{6}$ octahedra reaches a limit, conversion to the lithium niobate phase occurs with a displacive-type phase transition. In contrast, perovskites bearing large divalent cations, which is formally expressed as a tolerance factor of greater than one (as shown in Fig. 12.6), cannot make enough space for such large cations in tilting of $\mathrm{BO}_{6}$ octahedra. Therefore, silicate perovskites containing $\mathrm{Ca}^{2+}, \mathrm{Sr}^{2+}$, and $\mathrm{Ba}^{2+}$ cations are stabilized as hexagonal and/or cubic forms under high pressure [34-38]. These transformations have been confirmed by high-pressure experiments. The phase transition sequence is summarized in Table 12.2.

\subsubsection{Crystal Structures of Hexagonal Perovskite and Structural Relation with Cubic Perovskite}

Perovskites containing large divalent cations tend to expand and form a $\mathrm{BO}_{6}$ face-sharing octahedral framework to accommodate the large cations, where the $\mathrm{B}^{4+}$ ions in the face-sharing octahedra cause oxygen anions to move to closer to 
Fig. 12.6 Goldschmidt diagram with tolerance factor $(t)$ for $\mathrm{ABO}_{3}$ compounds. The solid line indicates $t=1$. The tolerance factors were calculated from the ionic radii of the six-fold coordinated B cations ( $x$ axis) and eight-fold coordinated A cations ( $y$ axis). Open diamonds are compounds that convert to the amorphous form under decompression. Solid and open squares are compounds that quench as the perovskite structure and convert to the lithium niobate structure at ambient pressure, respectively

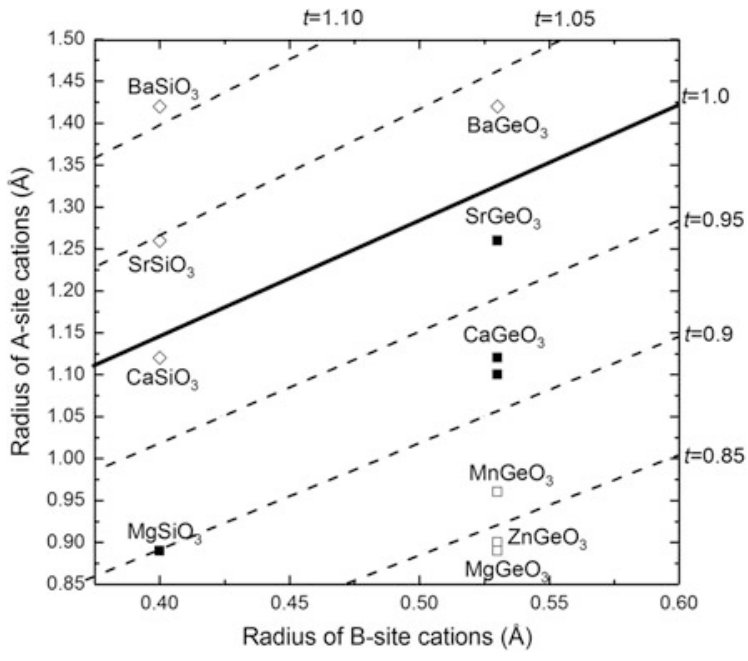

Table 12.2 High-pressure phase transition sequences of $\mathrm{ASiO}_{3}(\mathrm{~A}=\mathrm{Ca}, \mathrm{Sr}$, and $\mathrm{Ba})$ and transition pressures

\begin{tabular}{l|l|l}
\hline $\mathrm{CaSiO}_{3}$ & $\mathrm{SrSiO}_{3}$ & $\mathrm{BaSiO}_{3}$ \\
\hline wollastonite [39] & pseudowollastonite [40] & High-T $\mathrm{BaGeO}_{3}$ type [41] \\
\hline$\sim 3 \mathrm{GPa}$ & $\sim 4 \mathrm{GPa}$ & $\sim 4 \mathrm{GPa}$ \\
\hline walstromite [39, 42] & walstromite [43] & $\mathrm{BaSiO}_{3}(\mathrm{II})[44]$ \\
\hline$\sim 9 \mathrm{GPa}$ & $\sim 9 \mathrm{GPa}$ & $\sim 12 \mathrm{GPa}$ \\
\hline $\mathrm{Ca}_{2} \mathrm{SiO}_{4}+\mathrm{CaSi}_{2} \mathrm{O}_{5}[42]$ & $\mathrm{Sr}_{2} \mathrm{SiO}_{4}+\mathrm{SrSi}_{2} \mathrm{O}_{5}[36,45]$ & $\mathrm{Ba}_{2} \mathrm{SiO}_{4}+\mathrm{BaSi}_{2} \mathrm{O}_{5}[37]$ \\
\hline$\sim 13 \mathrm{GPa}$ & $\sim 20 \mathrm{GPa}$ & $\sim 18 \mathrm{GPa}$ \\
\hline cubic perovskite [34] & $6 \mathrm{H}$ perovskite [35] & $9 \mathrm{R}$ perovskite [37] \\
\hline & $\sim 38 \mathrm{GPa}$ & $\sim 40 \mathrm{GPa}$ \\
\hline & cubic perovskite [38] & $6 \mathrm{H}$ perovskite [37] \\
\hline & & $\sim 140 \mathrm{GPa}$ \\
\hline & & cubic perovskite [46]
\end{tabular}

reduce their repulsion. Stacking of the face-sharing framework in the $c$-axis direction results in a hexagonal unit cell. Examples of the hexagonal crystal structures of $\mathrm{BaSiO}_{3}$ [37] are shown in Fig. 12.7.

In Fig. 12.7, both the $\mathrm{SiO}_{6}$ octahedra and barium atoms are shown along the $c$ axis direction to clarify the relationships of the stacking sequences. The $9 \mathrm{R}$ phase (space group $R \overline{3} \mathrm{~m}$ ) resembles the $6 \mathrm{H}$ phase (space group $P 6_{3} / m m c$ ) in that the $\mathrm{SiO}_{6}$ octahedra are periodically connected by face sharing. The difference is the periodicity of the face- and corner-sharing of $\mathrm{SiO}_{6}$ octahedra. In the $c$-axis direction, 9R perovskite exhibits a $(c h h)_{3}$ sequence whereas $6 \mathrm{H}$ perovskite exhibits a $(c c h)_{2}$ sequence, where $c$ and $h$ correspond to corner- and face-sharing octahedra, respectively. For perovskites, It is known that such hexagonal polytypes lie in a 
sequence from 9R to $3 \mathrm{C}$ (space group $R \overline{3} m$ ) cubic perovskites. In this hexagonal sequence, pressure increases the frequency of corner-sharing octahedra. This relation can be extended to cubic perovskite (3C), which only consist of corner-sharing octahedral, as shown in Fig. 12.8. For $\mathrm{BaSiO}_{3}$, the density increases for the transitions from $9 \mathrm{R}$ to $6 \mathrm{H}$ and $6 \mathrm{H}$ to $3 \mathrm{C}$ are $3.5 \%$ and $1.4 \%$, respectively.

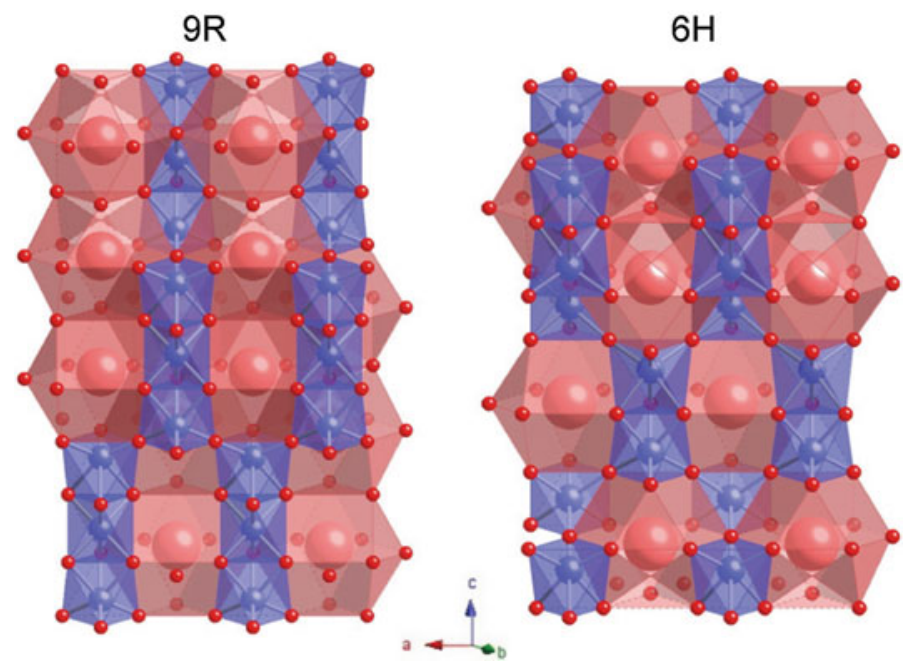

Fig. 12.7 Crystal structures of $9 \mathrm{R}$ and $6 \mathrm{H} \mathrm{BaSiO}_{3}$
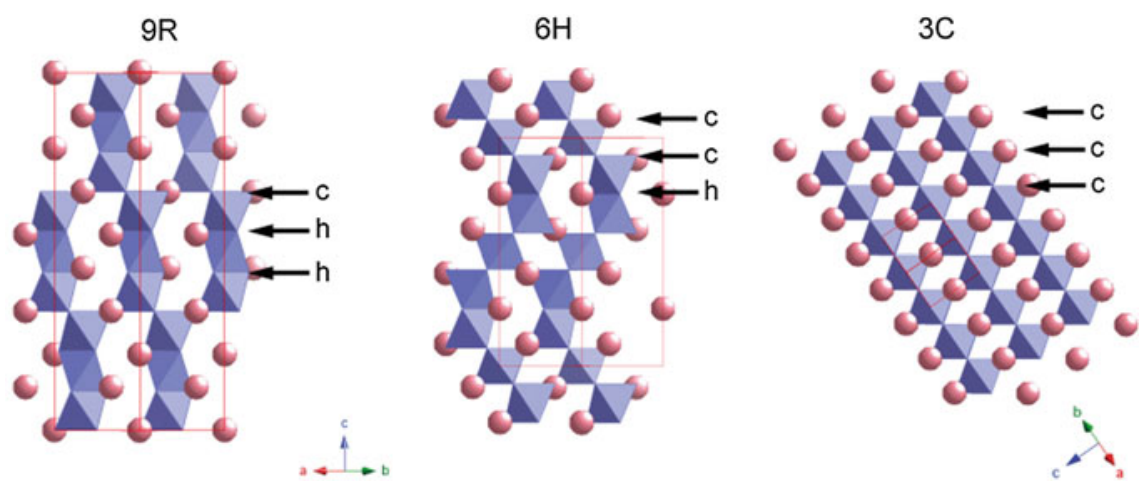

Fig. 12.8 Structural relationship among $9 \mathrm{R}, 6 \mathrm{H}$, and $3 \mathrm{C}$ perovskites in terms of the $\mathrm{BO}_{6}$ stacking sequence 


\subsubsection{Phase Diagrams: Experiments and Ab Initio Calculations}

The ionic radius can be controlled under high pressure. In particular, larger A-site cations in perovskites, such as $\mathrm{Sr}^{2+}$ and $\mathrm{Ba}^{2+}$, are sensitive to pressure. The A-site cations are compressed to $\mathrm{SiO}_{6}$ octahedra and the face-sharing octahedral frequency then gradually decreases with increasing pressure. Furthermore, as shown in the phase diagram based on high-pressure experiments in Fig. 12.9, for cubic perovskites, there is a systematic relation between the transition pressure and the $\mathrm{A}^{2+}$ radius. For the $\mathrm{BaSiO}_{3}$ compound, the transition occurs above $130 \mathrm{GPa}$ [46]. In contrast, the transitions of the cubic perovskites $\mathrm{CaSiO}_{3}$ and $\mathrm{SrSiO}_{3}$ occur at significantly lower pressures of 15 and $38 \mathrm{GPa}$, respectively. Note that $\mathrm{SrSiO}_{3}$ does not transform to a 9R-type hexagonal perovskite, such as that of $\mathrm{BaSiO}_{3}$. Furthermore, no hexagonal perovskites are found for $\mathrm{CaSiO}_{3}$. These results can be simply explained by the difference of the cation radii in the $\mathrm{A}$ sites.

Figure 12.10 shows the phase diagram of $\mathrm{BaSiO}_{3}$ at $0 \mathrm{~K}$ from ab initio calculations [46]. The phase transition sequence is consistent with that from high-pressure experiments, although the calculated transition pressures are underestimated.

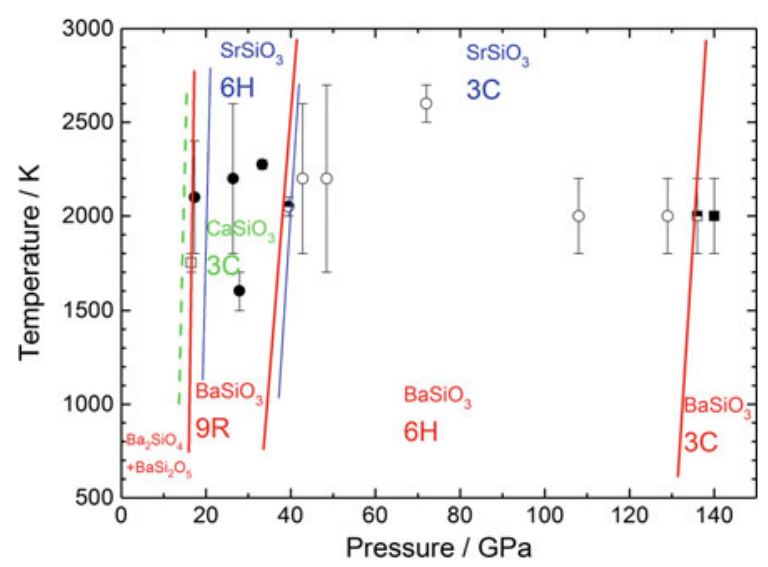

Fig. 12.9 Phase diagram of $\mathrm{BaSiO}_{3}$ estimated from data plots of high pressure-high temperature experiments using a laser-heated DAC. Solid circles, open circles, and solid squares represent 9R, $6 \mathrm{H}$, and $3 \mathrm{C}$ perovskites, respectively. Half-filled symbols indicate a phase mixture. The open square symbol at low pressure represents phase disproportionation of $\mathrm{Ba}_{2} \mathrm{SiO}_{4}+\mathrm{BaSi}_{2} \mathrm{O}_{5}$. The estimated phase boundaries of $\mathrm{BaSiO}_{3}$ (red solid lines), $\mathrm{SrSiO}_{3}$ (blue thin lines), and $\mathrm{CaSiO}_{3}$ (green broken line) are indicated for comparison 
Fig. 12.10 Relative enthalpy differences of the $\mathrm{BaSiO}_{3}$ phases [46] as a function of pressure. AP represents an ambient phase

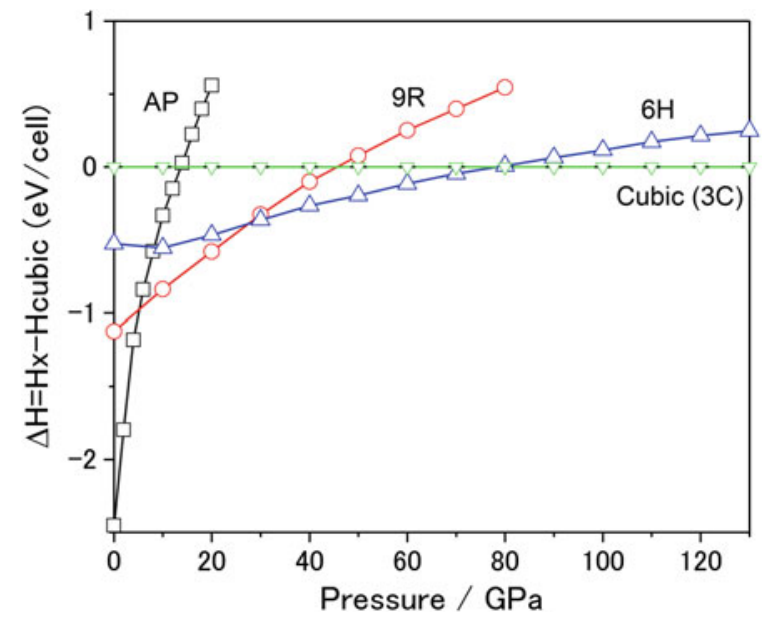

\subsubsection{Amorphization Under Decompression at Room Temperature}

In the cubic and hexagonal perovskites stabilized under high pressure, the A-site cations are compressed to retain the $\mathrm{BO}_{6}$ framework structure. In other words, the cations expand under decompression. Among the high-pressure phases of silicate perovskites, the first reported example was amorphization of $\mathrm{CaSiO}_{3}$ perovskite, which was confirmed at a pressure very close to $1 \mathrm{~atm}$. Because the ambient wollastonite phase is composed of $\mathrm{S} \mathrm{SiO}_{4}$ tetrahedral chain structure, the cubic perovskite structure cannot revert to the ambient structure at room temperature. The corner-sharing $\mathrm{BO}_{6}$ framework can be adjusted for smaller cations, as suggested by conversion to the lithium niobate structure. However, the framework is not as flexible for larger cations. Therefore, expansion of the A-site cations disrupts the framework and makes the structure amorphous. Amorphization of the cubic perovskite structure has also been observed for $\mathrm{SrSiO}_{3}$ [38] and $\mathrm{BaSiO}_{3}$ [46]. Considering the structural similarity, the hexagonal perovskite structures could become amorphous during decompression. The pressure for amorphization is believed to be related to the A-site cation size in the hexagonal structure because the $\mathrm{BO}_{6}$ face-sharing frequency of hexagonal perovskites is correlated with the cation size. The experimental results for $\mathrm{BaSiO}_{3}$ are shown in Fig. 12.11. The $6 \mathrm{H}$ phase begins to decompose at $21.9 \mathrm{GPa}$. In contrast, the $9 \mathrm{R}$ phase persists at $8.9 \mathrm{GPa}$ and suddenly changes to amorphous at $4.8 \mathrm{GPa}$. At $1.8 \mathrm{GPa}$, both of the phases completely change to amorphous. As a result, we can conclude that the stability of $9 \mathrm{R}$ is higher than that of $6 \mathrm{H}$. However, this type of amorphization has not been elucidated by computational approaches. If the ionic radii are determined under pressure, this type of structural instability related to amorphization could be clarified. 

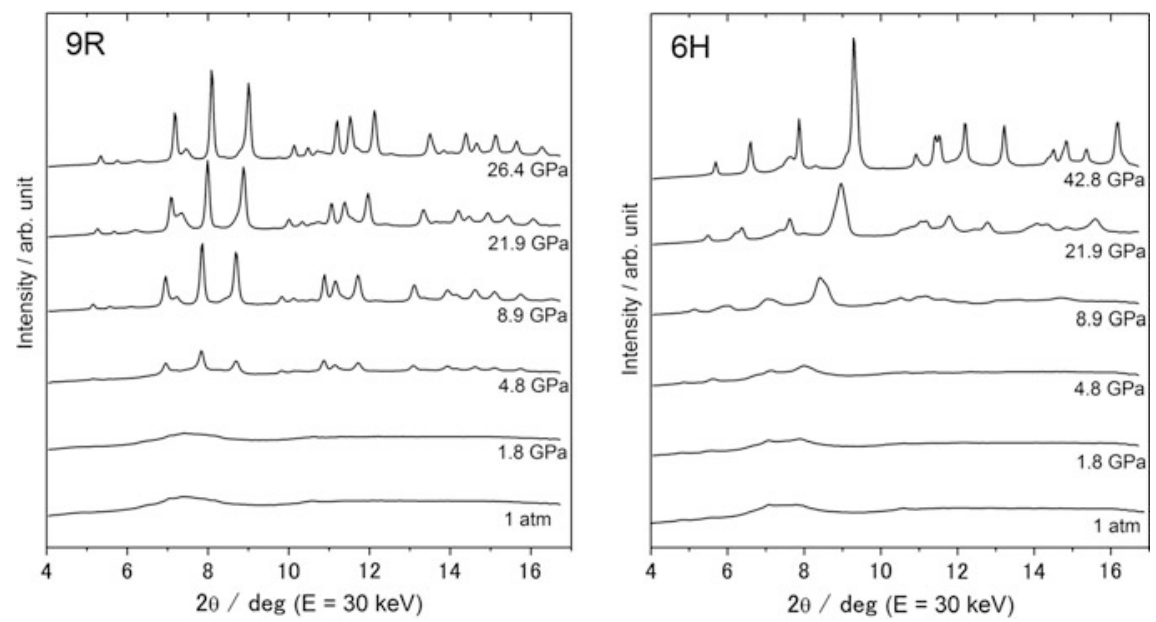

Fig. 12.11 In situ X-ray diffraction profiles of the $9 \mathrm{R}$ and $6 \mathrm{H}$ perovskites of $\mathrm{BaSiO}_{3}$ during decompression

\subsection{Relaxation Structures from the High-Pressure Phases of Sesquioxides}

\subsection{1 $\mathrm{Rh}_{2} \mathrm{O}_{3}(\mathrm{II})$ Structure Reverting to the Corundum Structure in Group 13 Sesquioxides}

Group-13 sesquioxides, such as aluminum oxide, gallium oxide, and indium oxide, have been widely investigated as attractive electroceramics. Their most stable phases under ambient conditions, corundum $\left(\mathrm{Al}_{2} \mathrm{O}_{3}\right)$, monoclinic $\beta-\mathrm{Ga}_{2} \mathrm{O}_{3}$, and cubic $\mathrm{In}_{2} \mathrm{O}_{3}$ (bixbyite-type structure, C-type rare earth sesquioxide structure, hereafter denoted as C-RES), are used for many application, such as lasers and transparent electronic devices [47, 48]. It is believed that their dense phase is the corundum structure [49]. However, in situ X-ray diffraction experiments have revealed that the $\mathrm{Rh}_{2} \mathrm{O}_{3}$ (II) structure that appears as a post-corundum phase under pressure reverts to the corundum structure under decompression. In $\mathrm{Al}_{2} \mathrm{O}_{3}$, the corundum structure that transforms to the $\mathrm{Rh}_{2} \mathrm{O}_{3}$ (II) phase under very high pressure above $95 \mathrm{GPa}$ reverts to the corundum structure at ambient pressure after decompression [50, 51]. In other instances, the $\mathrm{Rh}_{2} \mathrm{O}_{3}$ (II) phase in $\mathrm{Ga}_{2} \mathrm{O}_{3}$ identified under pressure transforms to the corundum phase after decompression rather than changing to $\beta-\mathrm{Ga}_{2} \mathrm{O}_{3}$ [52], as shown in Fig. 12.12.

Figure 12.13 shows the crystal structures of the $\mathrm{Rh}_{2} \mathrm{O}_{3}$ (II)-type and corundum structures of $\mathrm{Ga}_{2} \mathrm{O}_{3}$ with a specific direction for comparison. A twin-like relation between the $\mathrm{Rh}_{2} \mathrm{O}_{3}$ (II) and corundum phases can be seen in the vertical direction. Considering the structural resemblance between $\mathrm{Rh}_{2} \mathrm{O}_{3}$ (II) and corundum, we 


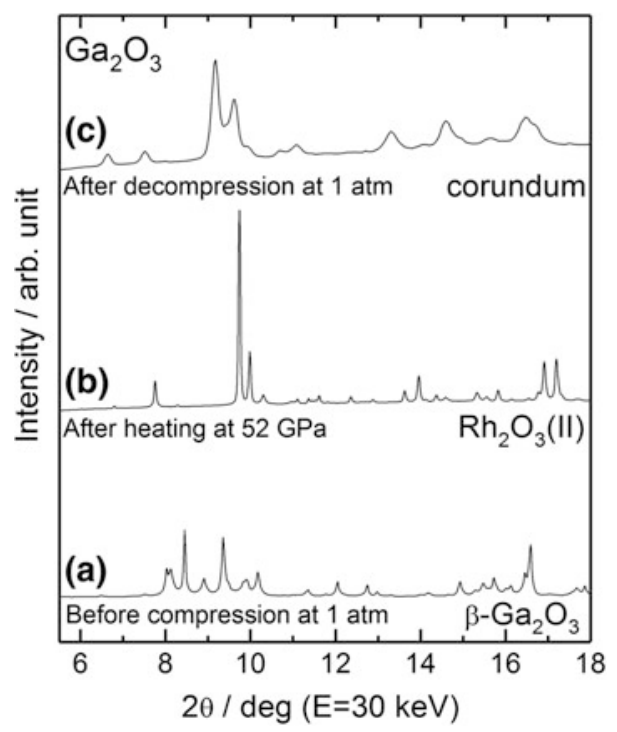

Fig. 12.12 X-ray diffraction profiles of $\mathrm{Ga}_{2} \mathrm{O}_{3}$ samples. a Starting $\beta-\mathrm{Ga}_{2} \mathrm{O}_{3}$ structure at ambient pressure, b $\mathrm{Rh}_{2} \mathrm{O}_{3}$ (II) structure after laser heating at $52 \mathrm{GPa}$, and (c) corundum structure after decompression at ambient pressure
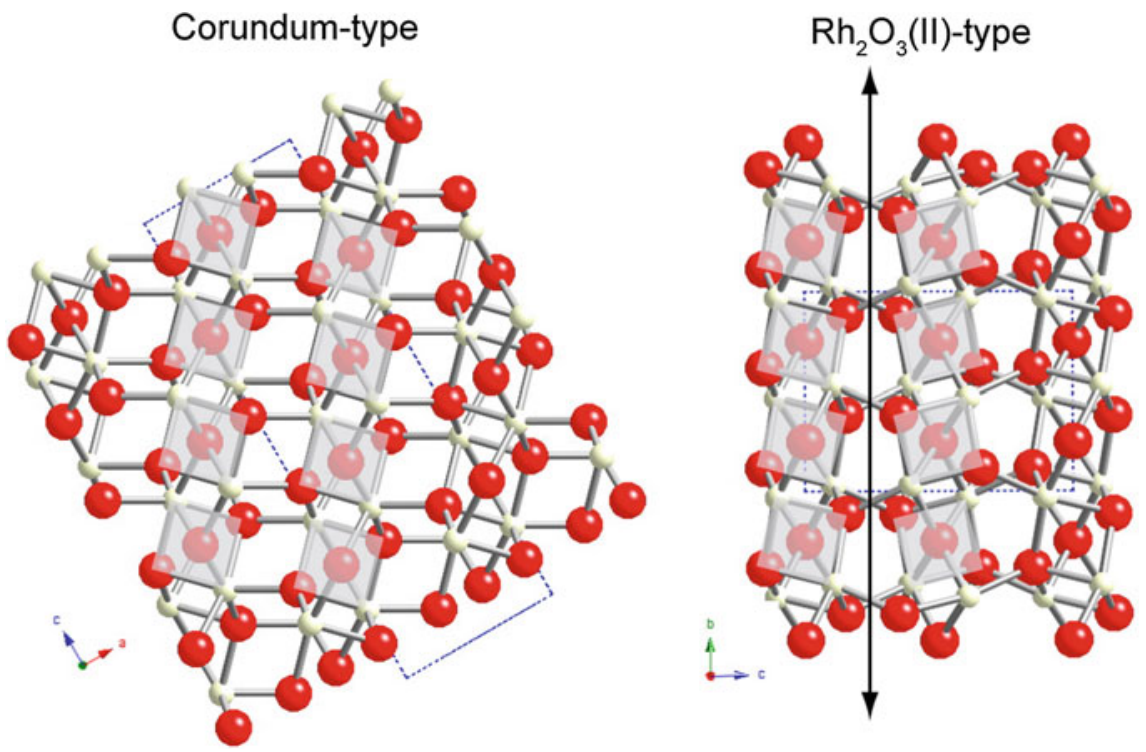

Fig. 12.13 Projections of the corundum structure of $\mathrm{Ga}_{2} \mathrm{O}_{3}$ along the hexagonal $a$ axis (left) and the $\mathrm{Rh}_{2} \mathrm{O}_{3}$ (II) structure of $\mathrm{Ga}_{2} \mathrm{O}_{3}$ along the $a$ axis (right) 


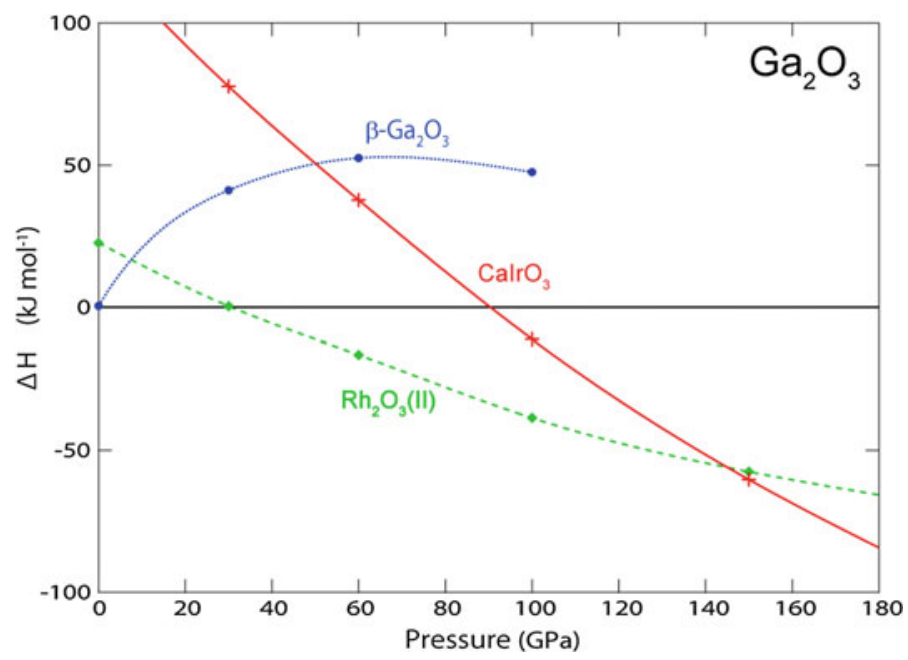

Fig. 12.14 Enthalpies of the $\mathrm{Ga}_{2} \mathrm{O}_{3}$ polymorphs relative to the corundum structure: $\beta-\mathrm{Ga}_{2} \mathrm{O}_{3}$ (blue circles), $\mathrm{Rh}_{2} \mathrm{O}_{3}$ (II) (green diamonds), and $\mathrm{CaIrO}_{3}$ (red crosses)

conclude that the $\mathrm{Rh}_{2} \mathrm{O}_{3}$ (II) structure is appropriate for the post-corundum phase of $\mathrm{Ga}_{2} \mathrm{O}_{3}$.

The differences in the static enthalpies of $\beta-\mathrm{Ga}_{2} \mathrm{O}_{3}$ and $\mathrm{Rh}_{2} \mathrm{O}_{3}$ (II)-type $\mathrm{Ga}_{2} \mathrm{O}_{3}$ relative to corundum-type $\mathrm{Ga}_{2} \mathrm{O}_{3}$ calculated by density functional theory (DFT) with the local density approximation(LDA) are shown in Fig. 12.14. The transitions from $\beta$ - $\mathrm{Ga}_{2} \mathrm{O}_{3}$ to corundum-type $\mathrm{Ga}_{2} \mathrm{O}_{3}$ and corundum-type $\mathrm{Ga}_{2} \mathrm{O}_{3}$ to $\mathrm{Rh}_{2} \mathrm{O}_{3}$ (II)-type $\mathrm{Ga}_{2} \mathrm{O}_{3}$ occur at about 0 and $30 \mathrm{GPa}$, respectively [52]. According to further phase investigation, the stability field continues to $130 \mathrm{GPa}$ until the $\mathrm{CaIrO}_{3}$-type structure appears [53].

For $\operatorname{In}_{2} \mathrm{O}_{3}$, in situ X-ray experiments reveal that the stability region for corundum phase is very narrow because the single corundum phase is not observed at any pressure [52]. This is consistent with the calculated results, which suggest the absence of a stability area for the corundum phase (Fig. 12.15) [52]. However, the recovered phase after decompression exhibits the corundum phase. Therefore, it can be concluded that the corundum phase appearing in the recovered sample is converted from the $\mathrm{Rh}_{2} \mathrm{O}_{3}$ (II) phase. The volume change from the $\mathrm{Rh}_{2} \mathrm{O}_{3}$ (II) phase to the corundum phase is estimated to be $2.1 \%$, which is comparable with the changes of $3.1 \%$ for $\mathrm{Al}_{2} \mathrm{O}_{3}$ [51] and $2.3 \%$ for $\mathrm{Ga}_{2} \mathrm{O}_{3}$. The $\mathrm{Rh}_{2} \mathrm{O}_{3}$ (II) phase does not transform to the $\mathrm{CaIrO}_{3}$ structure, which had been predicted by a computational study [54]. Instead, a more dense and higher coordinated phase with the $\mathrm{Gd}_{2} \mathrm{~S}_{3}$-type structure has been confirmed at about $40 \mathrm{GPa}$ from an experimental and computational study [55]. The enthalpy relations from DFT calculations are shown in Fig. 12.15. 


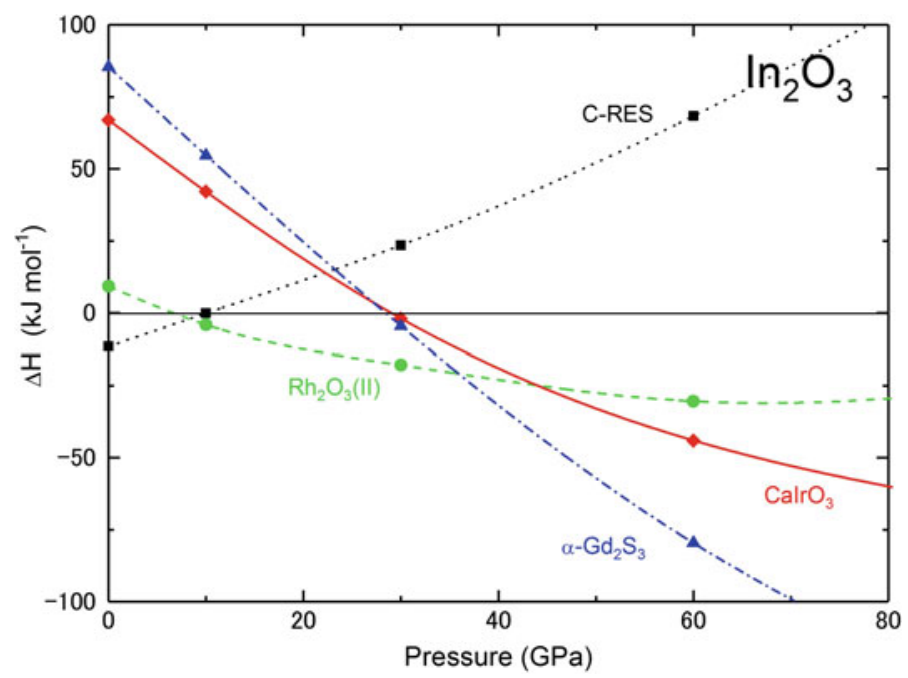

Fig. 12.15 Enthalpies of the $\operatorname{In}_{2} \mathrm{O}_{3}$ polymorphs relative to the corundum structure: C-RES (black squares), $\mathrm{Rh}_{2} \mathrm{O}_{3}$ (II) (green circles), $\mathrm{Gd}_{2} \mathrm{~S}_{3}$ (blue triangles), and $\mathrm{CaIrO}_{3}$ (red diamonds)

\subsubsection{A-RES Structure of $\mathrm{Y}_{2} \mathrm{O}_{3}$ Reverting to the B-RES Structure}

Yttrium has a similar ionic radius to the ionic radii of lanthanides, so lanthanide ions can be incorporated into yttria to make optical ceramics, such as $\mathrm{Eu}^{3+}: \mathrm{Y}_{2} \mathrm{O}_{3}$ phosphor [56] and $\mathrm{Yb}^{3+}: \mathrm{Y}_{2} \mathrm{O}_{3}$ laser [57]. Yttria crystallizes in the bixbyite structure (C-RES) under ambient conditions, similar to lanthanide sesquioxides. B-RES has been confirmed as the high-pressure phase in the recovery sample from high-pressure experiments. The A-RES phase was not found, which is expected to be part of the phase transformation sequence of lanthanide sesquioxides [58]. In situ X-ray diffraction experiments performed at room temperature using a DAC revealed the existence of the A-RES phase [59]. Back transformation to the B-RES structure was also confirmed. The reversible transformation mechanism from B-RES to A-RES can be explained from a crystallographic viewpoint, as shown in Fig. 12.16.

The B-RES structure of yttria consists of three different yttrium sites. Among these sites, only the Y3 site can be considered to possess six-fold oxygen coordination because the $\mathrm{Y} 3-\mathrm{O} 2$ distance is too long to be classified as seven-fold coordination, as shown in Fig. 12.16b. With increasing pressure, O2 moves closer to Y3, which results in the formation of seven-fold polyhedra. Upon further compression to $15-20 \mathrm{GPa}$, the $\mathrm{Y} 3-\mathrm{O} 2$ distance becomes shorter than the average $\mathrm{Y} 3-\mathrm{O}$ distance. The B-RES structure finally changes to the structure shown in Fig. 12.16c, which is equivalent to the A-RES structure. This means that the A-RES structure can be directly derived from the B-RES structure. The volume 


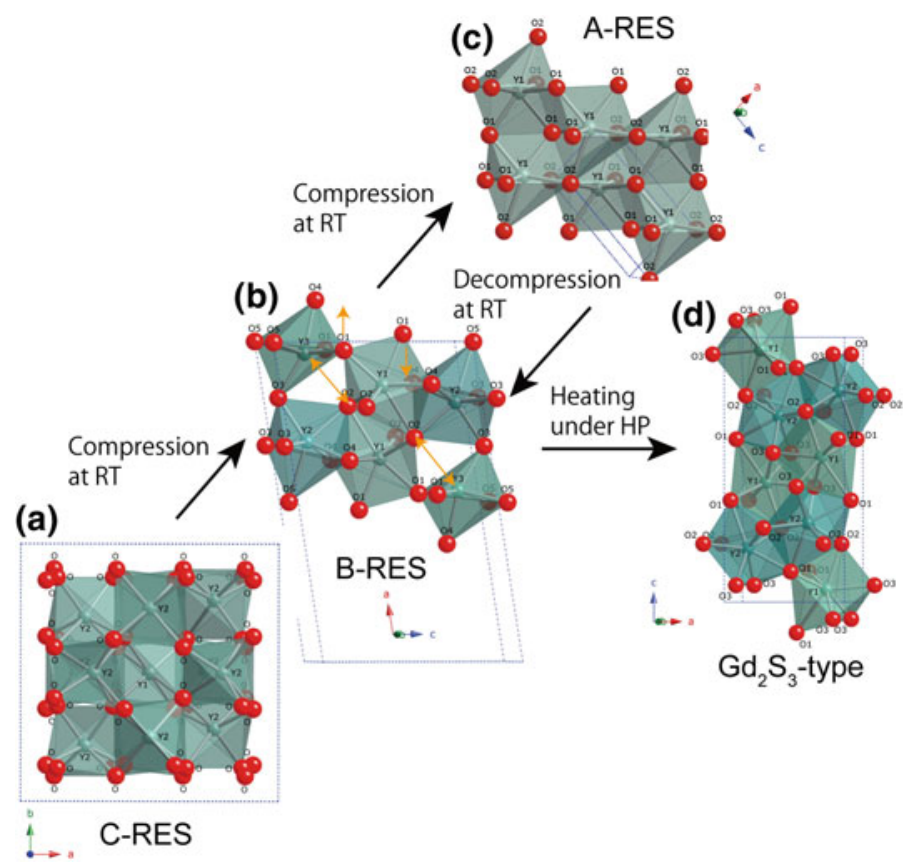

Fig. 12.16 Structural relationship among the high-pressure polymorphs of $\mathrm{Y}_{2} \mathrm{O}_{3}$

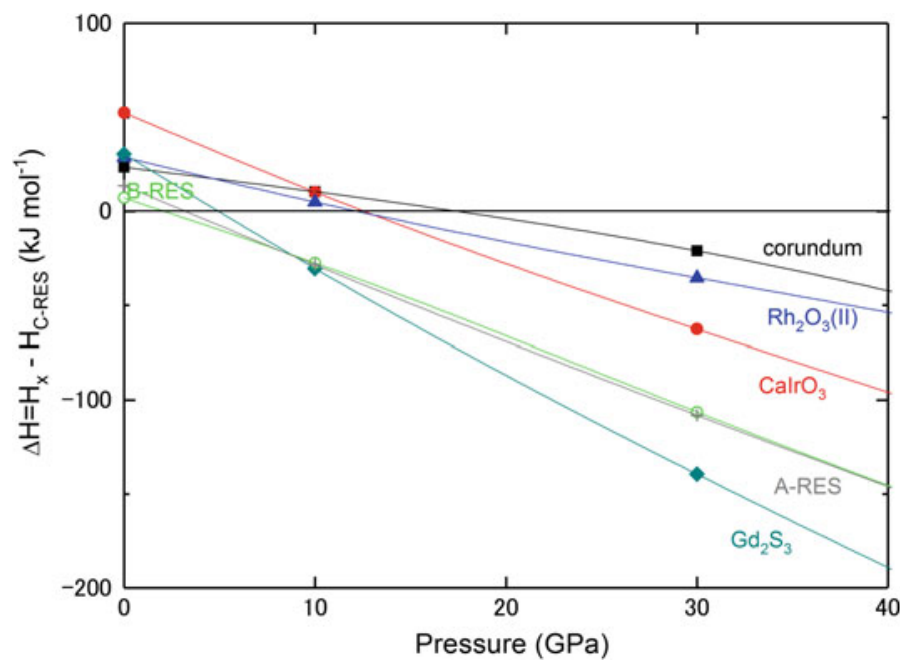

Fig. 12.17 Enthalpies of the $\mathrm{Y}_{2} \mathrm{O}_{3}$ polymorphs relative to the C-RES structure: B-RES (open green circles), A-RES (green crosses), $\mathrm{Gd}_{2} \mathrm{~S}_{3}$ (green diamonds), $\mathrm{CaIrO}_{3}$ (red circles), $\mathrm{Rh}_{2} \mathrm{O}_{3}$ (II) (blue triangles), and corundum (black squares) 
change from the B-RES structure to the A-RES structure (2.5\%) is characteristic of a first-order phase transition.

Contrary to confirmation of the A-RES structure by compression experiments at room temperature, enthalpy calculations performed by DFT with the LDA indicate no stability region of the A-RES structure (Fig. 12.17) [59]. The transition to the other high-coordination structure $\left(\mathrm{Gd}_{2} \mathrm{~S}_{3}\right.$-type structure, Fig. 12.16d) occurs before the appearance of the A-RES phase. In fact, laser heating experiments under high pressure result in $\mathrm{Y}_{2} \mathrm{O}_{3}$ crystallizing in the $\mathrm{Gd}_{2} \mathrm{~S}_{3}$ structure at about $10 \mathrm{GPa}$. Therefore, it can be concluded that the A-RES structure appearing under room temperature compression is a metastable phase.

\subsection{Concluding Remarks}

Large volume high-pressure apparatus (e.g., cubic, belt, and KAWAI-type presses) is a fundamental tool for materials scientists, because high-pressure methods enable the synthesis of novel materials under ambient conditions. High-pressure synthesis provides the opportunity to obtain high density and/or highly coordinated compounds. However, the recovered product does not always reflect the structure under pressure. If a new structure is found, the stability relation with the lower pressure phase(s) should be evaluated using computational approaches, such as ab initio calculations. If the structure is a metastable phase, the structure should be examined for crystallographic similarity with an objective structure. Conversion to the metastable phase would be clarified by structural relaxation. A trace amount of a high-pressure phase is sometimes found in the recovered products as a defect origination from twin structures. This is also an indication to identify the unquenchable high-pressure phase.

In situ X-ray diffraction is the most powerful approach to determine structures under pressure. In some cases, recompression of the metastable phase gives the high-pressure structure. During structural relaxation, symmetry change likely occurs, as exemplified by the transition from the perovskite to the lithium niobate phase as described in Sect. 12.2. Relaxation from a centrosymmetric to a non-centrosymmetric structure is important to determine the functionality, such as ferroelectricity.

As mentioned in Sect. 12.3, amorphization is a usual phenomenon for high-pressure products under decompression. Therefore, if there is a complete or part of an amorphous-like pattern in the X-ray diffraction profile of the recovered product, the amorphous structure is an indication of an unquenchable high-pressure phase. In situ X-ray experiments using a laser-heated DAC reveal the structure of the unquenchable phase. Amorphization can be triggered by the expansion of specific cations during decompression. In particular, elucidation of the compression behavior for relatively large cations, such as $\mathrm{K}^{+}, \mathrm{Ca}^{2+}, \mathrm{Sr}^{2+}$, and $\mathrm{Ba}^{2+}$, would aid in understanding the quenchability of high-pressure structures containing such cations. Therefore, an approach to determine the ionic radii under pressure is required for prediction of the quenchability. 
Acknowledgements I am deeply grateful to Prof. I. Tanaka and Dr. T. Taniguchi for their advice on the topics discussed in this chapter. I thank Profs. T. Tsuchiya and H. Hiramatsu for discussion on the computational studies. The X-ray diffraction experiments were performed under SPring-8 and KEK proposals. This work was supported in part by Innovative Areas "Nano Informatics" (Grant No. 25106006) and JSPS KAKENHI (Grant No. 16H04078).

\section{References}

1. H. Yusa, M. Akaogi, E. Ito, J. Geophys. Res.-Solid Earth 98, 6453 (1993)

2. M. Murakami, K. Hirose, K. Kawamura, N. Sata, Y. Ohishi, Science 304, 855 (2004)

3. M. Akaogi, E. Ito, Geophys. Res. Lett. 20, 1839 (1993)

4. Y. Hinatsu, T. Fujino, N. Edelstein, J. Solid State Chem. 99, 182 (1992)

5. R.J. Cava, A. Santoro, D.W. Murphy, S. Zahurak, R.S. Roth, J. Solid State Chem. 42, 251 (1982)

6. K. Leinenweber, W. Utsumi, Y. Tsuchida, T. Yagi, K. Kurita, Phys. Chem. Miner. 18, 244 (1991)

7. K. Leinenweber, Y.B. Wang, T. Yagi, H. Yusa, Am. Mineral. 79, 197 (1994)

8. J.A. Linton, Y.W. Fei, A. Navrotsky, Am. Mineral. 84, 1595 (1999)

9. H. Yusa, M. Akaogi, N. Sata, H. Kojitani, R. Yamamoto, Y. Ohishi, Phys. Chem. Miner. 33, 217 (2006)

10. Y. Inaguma, A. Aimi, Y. Shirako, D. Sakurai, D. Mori, H. Kojitani, M. Akaogi, M. Nakayama, J. Am. Chem. Soc. 136, 2748 (2014)

11. Y. Inaguma, M. Yoshida, T. Tsuchiya, A. Aimi, K. Tanaka, T. Katsumata, D. Mori, J. Phys: Conf. Ser. 215, 012131 (2010)

12. T. Hattori, T. Matsuda, T. Tsuchiya, T. Nagai, T. Yamanaka, Phys. Chem. Miner. 26, 212 (1999)

13. W. Wang, S. Wang, D. He, J.A. Xu, Solid State Commun. 196, 8 (2014)

14. Y. Inaguma, K. Tanaka, T. Tsuchiya, D. Mori, T. Katsumata, T. Ohba, K.-I. Hiraki, T. Takahashi, H. Saitoh, J. Am. Chem. Soc. 133, 16920 (2011)

15. V.M. Goldschmidt, Naturwissenschaften 14, 477 (1926)

16. R.D. Shannon, Acta Crystallographica Section A 32, 751 (1976)

17. M. O'keeffe, B.G. Hyde, J.O. Bovin, Phys. Chem. Miner. 4, 299 (1979)

18. Y. Zhao, D.J. Weidner, J.B. Parise, D.E. Cox, Phys. Earth Planet. Inter. 76, 17 (1993)

19. Y. Zhao, D.J. Weidner, J.B. Parise, D.E. Cox, Phys. Earth Planet. Inter. 76, 1 (1993)

20. S. Sasaki, C.T. Prewitt, R.C. Liebermann, Am. Mineral. 68, 1189 (1983)

21. J. Susaki, Phys. Chem. Miner. 16, 634 (1989)

22. H. Yusa, T. Tsuchiya, M. Akaogi, H. Kojitani, D. Yamazaki, N. Hirao, Y. Ohishi, T. Kikegawa, Inorg. Chem. 53, 11732 (2014)

23. S. Sasaki, C.T. Prewitt, J.D. Bass, W.A. Schulze, Acta Crystallogr. Sect. C-Struct. Chem. 43, 1668 (1987)

24. N.L. Ross, J.D. Ko, C.T. Prewitt, Phys. Chem. Miner. 16, 621 (1989)

25. A. Smith, Acta Crystallogr. 13, 749 (1960)

26. K. Fujino, D. Nishio-Hamane, K. Suzuki, H. Izumi, Y. Seto, T. Nagai, Phys. Earth Planet. Inter. 177, 147 (2009)

27. M. Akaogi, K. Abe, H. Yusa, H. Kojitani, D. Mori, Y. Inaguma, Phys. Chem. Miner. 42, 421 (2015)

28. J. Zhao, N.L. Ross, R.J. Angel, Phys. Chem. Miner. 31, 299 (2004)

29. H. Horiuchi, E. Ito, D.J. Weidner, Am. Mineral. 72, 357 (1987)

30. Y. Inaguma, M. Yoshida, T. Tsuchiya, A. Aimi, K. Tanaka, T. Katsumata, D. Mori, J. Phys: Conf. Ser. 215, 012131 (2010)

31. F. Zhu, X. Wu, S. Qin, Solid State Commun. 152, 984 (2012) 
32. T. Tsuchiya, J. Tsuchiya, Phys. Rev. B 76, 092105 (2007)

33. A.M. Glazer, M. Ahtee, H.D. Megaw, Acta Crystallogr. Sect. A 28, S179 (1972)

34. H.K. Mao, L.C. Chen, R.J. Hemley, A.P. Jephcoat, Y. Wu, W.A. Bassett, J. Geophys. Res.Solid Earth Planets 94, 17889 (1989)

35. H. Yusa, M. Akaogi, N. Sata, H. Kojitani, Y. Kato, Y. Ohishi, Am. Mineral. 90, 1017 (2005)

36. M. Akaogi, H. Kojitani, H. Yusa, R. Yamamoto, M. Kido, K. Koyama, Phys. Chem. Miner. 32, 603 (2005)

37. H. Yusa, N. Sata, Y. Ohishi, Am. Mineral. 92, 648 (2007)

38. W.S. Xiao, D.Y. Tan, W. Zhou, J. Liu, J. Xu, Am. Mineral. 98, 2096 (2013)

39. T. Gasparik, K. Wolf, C.M. Smith, Am. Mineral. 79, 1219 (1994)

40. F. Nishi, Acta Crystallogr. Sect. C-Cryst. Struct. Commun. 53, 534 (1997)

41. W. Hilmer, Acta Crystallogr 15, 1101 (1962)

42. M. Akaogi, M. Yano, Y. Tejima, M. Iijima, H. Kojitani, Phys. Earth Planet. Inter. 143, 145 (2004)

43. K. Machida, G. Adachi, J. Shiokawa, M. Shimada, M. Koizumi, K. Suito, A. Onodera, Inorg. Chem. 21, 1512 (1982)

44. Y. Shimizu, Y. Syono, S. Akimoto, High Temperatures-High Pressures 2, 113 (1970)

45. H. Kojitani, M. Kido, M. Akaogi, Phys. Chem. Miner. 32, 290 (2005)

46. H. Hiramatsu, Y. Hitoshi, I. Ryo, O. Yasuo, T. Kamiya, H. Hosono, Inorg. Chem. 56 (2017)

47. K. Matsuzaki, H. Yanagi, T. Kamiya, H. Hiramatsu, K. Nomura, M. Hirano, H. Hosono, Appl. Phys. Lett. 88, 092106 (2006)

48. H. Ohta, K. Nomura, H. Hiramatsu, K. Ueda, T. Kamiya, M. Hirano, H. Hosono, Solid-State Electron. 47, 2261 (2003)

49. C.T. Prewitt, R.D. Shannon, D.B. Rogers, A.W. Sleight, Inorg. Chem. 8, 1985 (1969)

50. N. Funamori, R. Jeanloz, Science 278, 1109 (1997)

51. J.F. Lin, O. Degtyareva, C.T. Prewitt, P. Dera, N. Sata, E. Gregoryanz, H.K. Mao, R. J. Hemley, Nat. Mater. 3, 389 (2004)

52. H. Yusa, T. Tsuchiya, N. Sata, Y. Ohishi, Phys. Rev. B 77 (2008)

53. T. Tsuchiya, H. Yusa, J. Tsuchiya, Phys. Rev. B 76 (2007)

54. R. Caracas, R.E. Cohen, Phys. Rev. B 76, 184101 (2007)

55. H. Yusa, T. Tsuchiya, J. Tsuchiya, N. Sata, Y. Ohishi, Phys. Rev. B 78 (2008)

56. S.L. Jones, D. Kumar, R.K. Singh, P.H. Holloway, Appl. Phys. Lett. 71, 404 (1997)

57. J. Kong et al., Appl. Phys. Lett. 82, 2556 (2003)

58. V.M.U. Goldschmidt, F. Barth, T.S.k.R, Nor, V. Akad. Kl. 1: Mat. Naturvindensk. 5 (1925)

59. H. Yusa, T. Tsuchiya, N. Sata, Y. Ohishi, Inorg. Chem. 49, 4478 (2010)

Open Access This chapter is licensed under the terms of the Creative Commons Attribution 4.0 International License (http://creativecommons.org/licenses/by/4.0/), which permits use, sharing, adaptation, distribution and reproduction in any medium or format, as long as you give appropriate credit to the original author(s) and the source, provide a link to the Creative Commons license and indicate if changes were made.

The images or other third party material in this chapter are included in the chapter's Creative Commons license, unless indicated otherwise in a credit line to the material. If material is not included in the chapter's Creative Commons license and your intended use is not permitted by statutory regulation or exceeds the permitted use, you will need to obtain permission directly from the copyright holder. 